\title{
Teachers and Epilepsy in Saudi Arabia: Gaps in Knowledge and Potential Roles
}

\author{
Amal M Alkhotani $\mathbb{D}$ \\ Department of Medicine, Umm Al-Qura University, Makkah, Saudi Arabia \\ Correspondence: Amal M Alkhotani, Department of Medicine, Umm Al-Qura University, Makkah, Saudi Arabia, Email amkhotani@uqu.edu.sa
}

\begin{abstract}
In young children, epilepsy, a disorder marked by recurring seizures, is frequent. Schoolteachers play an important role in the development of young children and hence have a big impact on their psychosocial development. This study was carried out to examine the available data from Saudi Arabia in order to better understand the knowledge gap among Saudi instructors. Although schoolteachers' knowledge in Saudi Arabia has improved over time, such that they now have significant knowledge that can affect student performance, social skill development, future endeavors, and life quality, a significant percentage still believes that epilepsy is linked to psychiatric illness. Few teachers have obtained first-aid training in the area of seizure treatment. It is consequently vital to improve instructors' knowledge of seizure first aid. Teachers' understanding and attitudes concerning epilepsy could be improved by health education. Schoolteachers should get focused and guided health education to improve their knowledge of epilepsy and change their attitudes.
\end{abstract}

Keywords: epilepsy, teachers, awareness, seizures, young children, attitude, health education

\section{Introduction}

Epilepsy is among the most frequent neurological illnesses among children. ${ }^{1}$ It involves recurrent seizures caused by a paroxysmal, excessive electrical discharge of cortical neurons. ${ }^{2}$ Epilepsy is extremely common, affecting more than 50 million people worldwide. ${ }^{3}$ The reported prevalence of epilepsy is 6.54 per 1000 population in Saudi Arabia. ${ }^{4}$ Epilepsy has been shown to have a detrimental impact on a child's physical health, mental health, behavior, and academic performance. ${ }^{4-7}$ Furthermore, a seizure can occur at school, where teachers will be the first medical personnel on the scene. Teachers' epileptic and seizure first-aid expertise can significantly influence the health, performance, and social skill development of the children. ${ }^{8}$

Epilepsy is a disorder with severe emotional and economic implications due to its complexity. ${ }^{9}$ Poor community understanding, lack of awareness, and cultural attitudes and stigma are key issues that both health professionals and persons with epilepsy confront. ${ }^{10}$

Certain individuals believe epilepsy is contagious or contributes to learning difficulties. ${ }^{11,12}$ These and other erroneous beliefs are culturally reinforced. They can foster negative attitudes about people with epilepsy and practice, thus impairing the quality of life of epileptic patients and their families. ${ }^{12}$

In social settings such as schools, children with epilepsy are subjected to erroneous views. Some epileptic adolescents struggle in school, while others have trouble learning and interacting with others. These difficulties may be caused not only by epilepsy but also by few factors such as the teacher's level of education, low expectations, rejection by teachers, parents, peers, and the child's low self-esteem. ${ }^{9}$ Even in relatively well-informed populations, disinformation and misunderstanding still exist.

Teachers in schools serve as crucial role models for students and have a long-term impact. Teachers' views may affect children's educational success, particularly those with epilepsy. ${ }^{9,13}$

Despite the importance of the teacher's involvement in the lives of these students, little study has been done in Saudi Arabia to evaluate these difficulties. ${ }^{14,15}$ Abulhamail et $\mathrm{al}^{15}$ revealed in recent Saudi research that primary schoolteachers' understanding of epilepsy needed to be improved, and epilepsy educational initiatives were needed. 
In Saudi Arabia, schools are divided into three educational levels (primary, secondary, and high schools). Children with epilepsy study in regular schools unless they have other associated disabilities. Schoolteachers are the primary contact for students in class, and schools rarely have nurses or medical personnel available at all times. Instead, one of the teachers has the responsibility for school health. The Ministry of Education's school health unit aims to promote students' and teachers' health by coordinating health practitioners and schools. Therefore, the present study aims to review available data from Saudi Arabia to understand the gap in teachers' knowledge of epilepsy.

The search strategy was performed in which all the relevant papers published in 20 years were included by searching through on Pub Med, Central, and Google scholar by using keywords epilepsy, teachers, awareness, seizures, young children, attitude, health education. The published articles in this context from Saudi Arabia and other regions for identifying the challenges and gaps were included.

\section{Potential Role of Teachers Towards Dealing Epilepsy}

Many school-aged children with epilepsy exhibit educational difficulties prior to their first seizure, implying that an opportunity for early identification was missed. ${ }^{9,16}$ Because children spend the majority of their waking hours at school, it is critical to diagnose behavioural and cognitive impairments associated with epileptic seizures. Unexpected declines in academic performance, coupled with attention lapses, may be the first sign of undiagnosed epilepsy. Of course, there is a risk that children who spend an excessive amount of time daydreaming in class will be misclassified as absent. On the other hand, certain seizure-related abnormalities are so mild that they may manifest initially as behavioural or intellectual difficulties in the classroom. ${ }^{17}$

The transition to school is one of the most challenging issues for children with special needs, particularly neurological diseases such as epilepsy. This is true throughout the world, but it is challenging in impoverished nations, where even healthy children are sometimes denied admission to the school. ${ }^{18}$

The educator has a critical role in forming positive attitudes and solid mental attitudes about any condition or problem. In their training and professional teaching careers, schoolteachers do not get any formal epilepsy education. Despite their significance, school health services are frequently ignored in many areas of the globe, including Saudi Arabia, due to a lack of teacher understanding of first-aid care for common crises such as epileptic fits. ${ }^{19}$ In an emergency, teachers are also seen as the first line of defence for schoolchildren. They must be able to handle health emergencies in pupils efficiently. ${ }^{20}$

\section{Identifying Comorbid Conditions}

Epilepsy encompasses more than seizures. This may be more true in children than in any other age group, owing to the enormous cognitive demands of education and the various concomitant illnesses that typically occur with epilepsy. These comorbidities may be just as damaging to learning as the seizures themselves. Epilepsy in childhood is connected with neuropsychiatric and behavioral comorbidities, which affect around one-quarter to two-thirds of children with epilepsy. ${ }^{21}$ These comorbid disorders have a variety of etiologies, which include underlying brain injury, adverse effects of antiseizure drugs, epileptic activity, and the epileptogenic process of epilepsy. All of these comorbidities have one thing in common: they are all intimately tied to learning and the school environment. The behavioral comorbidities associated with epilepsy range from episodic issues associated with seizure prodromes to more persistent illnesses found in attention-deficit hyperactivity disorder (ADHD). ADHD is crucial in this setting since it has been confirmed to occur up to fifteen times more frequently in children with epilepsy than in the general population. ${ }^{22}$ The association between epilepsy and inattentive ADHD underscores the critical nature of a school-based diagnosis, as this type of ADHD may manifest only in the classroom. ${ }^{23}$

\section{Teachers' Knowledge and Attitude Toward Epilepsy in Saudi Arabia in Comparison to Other Countries}

Teachers' understanding of epilepsy was low in Japan, Kuwait, and Khartoum, ${ }^{9,24,25}$ whereas intermediate knowledge was found in Jordan. ${ }^{26}$ Teachers in Saudi Arabia, such as Riyadh and Khamis Mushait, have a high understanding of epilepsy. ${ }^{27}$ Teachers in Tabuk, Arar, and Makkah, on the other hand, were found to have insufficient knowledge of 
epilepsy in studies. ${ }^{28-30}$ Furthermore, all prior national studies that evaluated seizure first aid practice found that it was ineffective. ${ }^{9,28-30}$

Eight studies have examined various aspects of teachers' knowledge and attitude across Saudi Arabia, finding that 80$100 \%$ of teachers have heard about epilepsy. ${ }^{31,32}$ The understanding of epilepsy has improved over time. In the early study in 2012 reported by Obeid, $40.3 \%$ of teachers thought that epilepsy is caused by "jinn possession". 33 More recent studies from 2015-2021 have shown that only $1.4 \%$ to $6.6 \%$ believe it is related to the supernatural or jinn possession. ${ }^{30,34,35}$ Those that believe that it is a psychiatric disease is still high. Two studies in Tabuk and Taif found that $56.4 \%$ to $59 \%$ of the studied teachers thought it was a psychological disorder. ${ }^{29,31}$ There has been a significant change in the knowledge of the cause of epilepsy over time. The majority of recent studies have shown that most teachers believe it is related to a neurological disorder. $^{30,35}$ Most teachers agree that it is not contiguous. ${ }^{29,31}$ In a study in which teachers' knowledge was scored, the mean score of teachers' understanding of epilepsy was 7 out of 8 with a range from $3-8 .^{32}$

Several variables are associated with a better knowledge of epilepsy, including years of experience $(\mathrm{P}<0.000001)$, young age $(\mathrm{P}=0.0000486)$, higher education $(\mathrm{P}=0.02738)$, and secondary schoolteachers in comparison with intermediate teachers $(\mathrm{P}=0.00643)$. A systematic analysis examining teachers' knowledge of epilepsy showed a positive correlation between a higher level of education and expertise, whereas years of experience showed an inconsistent effect on knowledge. ${ }^{36}$

Teachers' increased awareness of epilepsy aetiology is reflected in their increased comprehension of treatment options for epileptic patients. The majority of educators were aware that epilepsy can be successfully treated (73\% to $91 \%) .30,33$ Although the use of traditional medicine has declined in recent years, such primitive culture-based erroneous beliefs regarding epilepsy have long been eradicated in many sophisticated countries ${ }^{32}$ despite the fact that a sizable proportion of teachers continue to believe it is used to treat epilepsy.

A study from 2012 showed that $67.5 \%$ used Ruqia, 10.4\% used cauterization and 10.4\% cupping as a treatment of epilepsy. ${ }^{33}$ This has since decreased to $32.4 \%$ for Ruqia, $8.1 \%$ for traditional healing, and $1.4 \%$ for cauterization in $2022 .{ }^{32}$ This finding reflects the generalized public perception of epilepsy treatment. A recent systematic review published in 2021 studying the perception of epilepsy in Saudi Arabia showed that around 18\% of people still think that herbal medicine is a treatment of choice and 39.3\% think that Quran or spiritual treatment is a treatment of choice. ${ }^{37}$ As most people in Saudi Arabia are devout Muslims, a high percentage still consider the role of traditional medicine in the treatment of epilepsy increased. Hence, there is a need to raise awareness that epilepsy is a disease that requires medical therapy. Indeed, although no evidence has shown that traditional treatment is effective for treating epilepsy, a study of Ethiopian teachers found that $18.5 \%$ believed that patients should be treated in church, $4.4 \%$ by the Quran, $34.1 \%$ by holy water, and $3.6 \%$ by traditional therapy. ${ }^{38}$ Another study from Niger found that $31.7 \%$ believed in conventional treatment, and $21.4 \%$ preferred a combination of conventional and medical treatment. ${ }^{39}$

Studies of teachers' attitudes toward epileptic patients have examined different aspects including general attituderelated questions such as marriage, employment, having children, discrimination, and driving and more specific questions related to students' attitudes. Only $12 \%$ to $14.3 \%$ of teachers think that epileptic children should be in special schools. $^{32,39}$ The majority of teachers treat epileptic children as regular students or as other children with chronic diseases. $^{32,39}$ Sympathy for such patients varies between $12.6 \%$ and $63.1 \%{ }^{32,39}$ A younger age $(\mathrm{P}<0.000001)$ and more years of experience $(\mathrm{P}<0.000001)$ are significant factors associated with a better attitude toward epileptic patients. In terms of the general attitude toward epilepsy, there is a negative attitude. Only $78-79 \%$ think that a patient with epilepsy can get married, while $62-67 \%$ believe that a patient can have children. Only $23-24 \%$ would marry someone with epilepsy, and 32-36\% would approve of their son/daughter marrying an epileptic patient. Around half (48-54\%) would support their children playing with an epileptic child. Despite this negative attitude, around 22-23\% believe that an epileptic patient suffers from discrimination. ${ }^{29,31}$ The negative attitude of teachers is similar to of the public in Saudi Arabia, where only 34.6\% (95\% CI 26.9-43.1) would approve of their son/daughter marrying someone with epilepsy. ${ }^{37}$

Compared to teachers in other nations, a study in Niger showed that $15.8 \%$ have a low level of knowledge and attitudes, $66.2 \%$ a medium level, and $18 \%$ a high level. ${ }^{40}$ In this study, $73.2 \%$ of respondents would not allow their children to marry a patient with epilepsy. In a study in Sudan, 53.8\% of teachers deal with epileptic patients as ordinary people, $64.2 \%$ believe that an epileptic patient can get married and have children, and $46.2 \%$ think that an epileptic patient can carry out daily activities and work. ${ }^{9}$ Teachers in Tunisia have more positive attitudes toward epilepsy $(72.85 \%$ 
$=$ mean attitude score); $95 \%$ of those teachers think that epileptic patients can get married and have children. However, no question on allowing one's son/daughter to marry epileptic patients was asked. ${ }^{41} \mathrm{~A}$ similar finding was reported in a study in Kuwait. ${ }^{25}$ The differences between these nations represent the public perception and degree of education and resources. Each year, programmes to raise awareness of epilepsy are held; yet, a considerable lack of understanding and a negative attitude toward epilepsy persist. By interacting with young children, schoolteachers can also contribute to changing public perceptions of epilepsy by developing the next generation. Enhancing their knowledge and viewpoint would contribute to a more positive public perception in developing ages. This would thus contribute to reducing the stigma associated with epilepsy and improving young people's attitudes toward epileptic sufferers.

\section{Knowledge of First Aid Management for Acute Seizures}

Patients with epilepsy are at risk of having a seizure at any time. This can happen at home, in school, or on the street. People witnessing an epileptic seizure might be frightened, and harmful measures could mistakenly be taken. One of the major misconceptions during an epileptic fit is that the patient may swallow their tongue. Another common mistake is to hold the patient down to stop abnormal movements. Some people may mistake a seizure with a cardiac arrest, leading to unnecessary actions. ${ }^{42}$ During an epileptic seizure, the assister should keep the patient in a safe position and time the seizure. Once the seizure is over, they should place the patient in the recovery position and observe the level of consciousness. ${ }^{43}$

Due to the possibility of seizures occurring at school, instructors play a critical role in delivering adequate first aid. Additionally, they play a critical role in restraining the other children and assisting in minimizing the frightening scene. They should be able to determine when to summon assistance and when to transport the patient to the hospital. An epileptic patient experiencing a seizure does not require hospitalization unless the episode is lengthy or the patient experiences recurrent seizures without regaining consciousness. These people are at risk of developing status epilepticus and a lasting disability as a result of a prolonged seizure. ${ }^{44}$

Among the teachers studied in Saudi Arabia, 31.7\% to 69.3\% have witnessed a seizure previously. ${ }^{29,34}$ However, only $8-11 \%$ have received seizure first aid training. ${ }^{36,37}$ Altogether, $54.6 \%$ of teachers would feel scared watching an epileptic fit. ${ }^{29}$ The results on first aid responses varied. Although $37.3-60 \%$ know the correct answer to ensure patient safety, a substantial percentage (36.2-55\%) said they would open the patient's mouth and put an object in. ${ }^{36,37}$ Having fewer years of experience is associated with a better first aid response e $(\mathrm{P}<0.001) .{ }^{36}$ In terms of post-event care putting the patient in the recovery position is recognized as the appropriate response by $47.9-64 \%$ of the studied teachers. ${ }^{36,37}$ More experienced teachers provide a significantly more appropriate response than less experienced teachers. ${ }^{36}$

One area that requires improvement is the indication of deciding to transfer to a hospital $(30.4-45 \%$ among the studied teachers). ${ }^{36,37}$ Having both more experience and a postgraduate qualification are recognized as significant factors associated with responding appropriately. ${ }^{36}$ Kango found a positive relationship between the knowledge score on managing an epileptic fit and level of education. More educated teachers have higher knowledge scores than less educated ones. No significant relation with years of experience was found in that study, likely reflecting the sample of teachers who were mostly above 30 years. ${ }^{37}$ In Saudi Arabia, no studies have been conducted on teachers' abilities or experience administering emergency medication.

Several countries have adopted rescue medications for prolonged seizures, including France, the United Kingdom, and Germany. In those countries, a guideline has been developed to ensure that epileptic child can receive their rescue medications if they suffer a seizure in school. Schoolteachers and other school staff are responsible for delivering those medications to a child. However, this is not well used in practice. A lack of knowledge and fear of liability remains significant limitations. ${ }^{45}$ Saudi Arabia lacks such a guideline at present. When a child is known to have epilepsy and be at risk of developing status epilepticus, parents should provide all the clinical information to school staff. The use of rescue medication can be taught to staff until further guidelines are developed.

\section{Summary of Evidence}

The study aimed to focus on teachers' knowledge of epilepsy in Saudi Arabia. Epilepsy and its manifestations impact children's quality of life, particularly building relationships, mental health, and academic success in school. ${ }^{5-7}$ As a result, instructors must be aware of how to cope with this sickness and lessen the burden on the affected kid. 
No study in Saudi Arabia has thus far examined the effect of educational programs on teachers' knowledge of epilepsy. Several studies have shown the impact of health education on teachers' understanding of and attitude toward epilepsy. The educational programs used include lectures, ${ }^{46,47}$ workshops,${ }^{48}$ short videos, ${ }^{49}$ and pamphlets. ${ }^{50}$ The effect of health education has been studied both immediately and in the long term. Post-intervention data were evaluated immediately after the workshop and at three months in one study; another evaluated the response after 12 weeks.

It is critical for the school staff to design a unique seizure action plan for each student. This team should comprise parents, teachers, the school nurse, a physician, and any other professionals who can provide information about the student's health requirements. The establishment of a seizure action plan supports school workers in providing expedient medical treatment, potentially reducing the need for emergency department visits. The ultimate goals of a seizure action plan are to provide treatment, minimise class disruptions, and quickly return the kid to class. Other pupils in the class may be frightened and have questions and worries after witnessing their classmate experience a seizure. Without adequate information, pupils may be scared of the student with epilepsy and may even avoid him or her. With the approval of the student's parents and the student's consent, peers should be provided with factual, age-appropriate information to relieve their worries and encourage understanding and empathy. ${ }^{51}$

All studies have shown a positive impact of health education on raising knowledge, improving attitude, and enhancing the management of seizure first aid. Attitude toward epileptic patients' education, employment, and marriage also improved significantly after the intervention. This is the major area of concern found among Saudi teachers. The positive effect of health education thus has the potential to improve teachers' perception of and attitude toward epileptic patients.

In Saudi Arabian schools, a teacher is responsible for providing first aid to sick children. However, during an epileptic seizure, quick action is required to prevent unnecessary or harmful activities. It is also essential to control the other children in the class and respect the patient's privacy. Hence, we recommend an educational program given to all teachers to raise their awareness of dealing with an acute seizure and improve their knowledge of epilepsy.

An evaluation of schoolteachers' epilepsy-related knowledge indicated solid fundamental knowledge, particularly among senior personnel, but inadequate awareness of critical specifics. Teachers were well aware of their limited understanding. Because of the enormous stigma associated with epilepsy, their attitudes and actions regarding epilepsy were unfavorable. Teachers' negative views concerning epilepsy and their harmful actions and lack of information must be recognized by primary care physicians. This should aid in developing tailored health education materials for use in schools to reduce epilepsy-related stigma and increase teachers' awareness of the illness.

\section{Conclusion}

Teachers in Saudi Arabia have a good knowledge of seizure etiology and treatment. It is reported in the literature and could also be postulated from this review that years of experience and young age was significant associated with the improved knowledge and management of epilepsy, the awareness, psychological handling and first aid for epilepsy is directly associated with experience and young age. However, a specific attitude toward epileptic patients must be developed. It is necessary to improve teachers' responses to acute seizure first aid care. Teachers' lack of awareness and expertise of epilepsy has been observed in every country where they have been studied. Educational initiatives are frequently effective at altering individuals' attitudes and knowledge. However, higher-quality research with a more robust study design is necessary to gain a better understanding of the factors that contribute to negative attitudes and the most effective approaches to modify attitudes and knowledge. Public health activities should be directed toward schools in order to increase schoolteachers' awareness of epilepsy. To enhance teachers' attitudes and practices, longitudinal and large-scale research should be done. Qualitative techniques and theme analysis should be employed in the investigation of teacher attitudes, knowledge, and practices. Epilepsy and other common medical conditions should be incorporated into university courses for education students and should be a required component of teacher education. Epilepsy communication initiatives should be innovative in their approach to providing accurate information using social media and government-sponsored media. To aid in the development of effective treatments to close expected gaps prior to graduation, research on attitudes, beliefs, and knowledge should also be conducted on undergraduate university students.

Future research should be longitudinal, assessing trends in epilepsy knowledge, attitude, and practice over extended periods of time. There is a dearth of qualitative research, and future studies might employ theme analysis and 
triangulation to elicit detailed information regarding teachers' perceptions of epilepsy in Saudi Arabia. Effective interventions are urgently needed to raise awareness, soften attitudes, and correct current epilepsy-related behaviors. As a result, research on these therapies should be undertaken using sound methodology.

\section{Acknowledgments}

The author would like to thank the deanship of Scientific Research of Umm Al-Qura University for supporting this work by grant code: 19-MED-1-03-0019.

\section{Disclosure}

The author received a research fund to support this work from the Deanship of Scientific Research of Umm Al-Qura University by grant code: 19-MED-1-03-0019 and reports no conflicts of interest in this work.

\section{References}

1. Rubenstein S, Levy A. Seizures in childhood: aetiology, diagnosis, treatment, and what the future may hold. Neurology. 2019;7:62-70.

2. Auer T, Schroeppel P, Erker T, et al. Impaired chloride homeostasis in epilepsy: molecular basis, impact on treatment, and current treatment approaches. Pharmacol Ther. 2020;205:107422. doi:10.1016/j.pharmthera.2019.107422

3. Epilepsy [Internet]; [cited June 28, 2020]. Available from: https://www.who.int/news-room/fact-sheets/detail/epilepsy. Accessed January 15, 2022.

4. Al Rajeh S, Awada A, Bademosi O, et al. The prevalence of epilepsy and other seizure disorders in an Arab population: a community-based study. Seizure. 2001;10(6):410-414. doi:10.1053/seiz.2001.0602

5. Chong L, Jamieson NJ, Gill D, et al. Children's experiences of epilepsy: a systematic review of qualitative studies. Pediatrics. 2016;138(3). doi:10.1542/peds.2016-0658

6. Sbarra DA, Rimm-Kaufman SE, Pianta RC. The behavioral and emotional correlates of epilepsy in adolescence: a 7-year follow-up study. Epilepsy Behav. 2002;3:358-367. doi:10.1016/S1525-5050(02)00035-5

7. Quintas R, Raggi A, Giovannetti AM, et al. Psychosocial difficulties in people with epilepsy: a systematic review of literature from 2005 until 2010. Epilepsy Behav. 2012;25:60-67. doi:10.1016/j.yebeh.2012.05.016

8. Hsieh LP, Chiou HH. Comparison of epilepsy and asthma perception among preschool teachers in Taiwan. Epilepsia. 2001;42:647-650. doi:10.1046/j.1528-1157.2001.39200.x

9. Elhassan MA, Alemairy AA, Amara ZM, et al. Epilepsy: knowledge, attitude, and practice among secondary school teachers in Khartoum State. Neurol Ther. 2017;6:225-235. doi:10.1007/s40120-017-0083-7

10. Ngugi AK, Bottomley C, Kleinschmidt I, et al. Estimation of the burden of active and life-time epilepsy: a meta-analytic approach. Epilepsia. 2010;51(5):883-890. doi:10.1111/j.1528-1167.2009.02481.x

11. Asato MR, Doss JL, Plioplys S. Clinic-friendly screening for cognitive and mental health problems in school-aged youth with epilepsy. Epilepsy Behav. 2015;48:97-102. doi:10.1016/j.yebeh.2015.03.033

12. Szemere E, Jokeit H. Quality of life is social-towards an improvement of social abilities in patients with epilepsy. Seizure. 2015;26:12-21. doi:10.1016/j.seizure.2014.12.008

13. Ojinnaka NC. Teachers' perception of epilepsy in Nigeria: a community-based study. Seizure. 2002;11:386-391. doi:10.1053/seiz.2001.0664

14. Alaqeel A, Sabbagh AJ. Epilepsy; what do Saudi's living in Riyadh know? Seizure. 2013;22:205-209. doi:10.1016/j.seizure.2012.12.010

15. Abulhamail AS, Al-Sulami FE, Alnouri MA, et al. Primary school teacher's knowledge and attitudes toward children with epilepsy. Seizure. 2014;23:280-283. doi:10.1016/j.seizure.2013.12.010

16. Berg AT, Smith SN, Frobish D, et al. Special education needs of children with newly diagnosed epilepsy. Dev Med Child Neurol. $2005 ; 47: 749-753$. doi:10.1111/j.1469-8749.2005.tb01072.x

17. Huisman J, Smits J. Effects of household-and district-level factors on primary school enrollment in 30 developing countries. World Dev. 2009;37:179-193. doi:10.1016/j.worlddev.2008.01.007

18. Antoninus M. Tackling the largest global education challenge? Secular and religious education in northern Nigeria. World Dev. 2014;59:82-92. doi:10.1016/j.worlddev.2014.01.017

19. Bhatia V, Puri S, Mangat C, et al. An intervention study to strengthen first aid care in schools of Chandigarh, India. Int J Fam Pract. 2010;8:1-8.

20. Aljehani MS. Level of knowledge of first aid of epilepsy among female teachers of elementary schools in Makkah city, Saudi Arabia. Int J Med Dev Countries. 2019;59-64. doi:10.24911/IJMDC.51-1562256348

21. Burton K, Rogathe J, Whittaker RG, et al. Co-morbidity of epilepsy in Tanzanian children: a community-based case-control study. Seizure. 2012;21 (3):169-174. doi:10.1016/j.seizure.2011.10.011

22. Hesdorffer DC, Ludvigsson P, Olafsson E, Gudmundsson G, Kjartansson O, Hauser WA. ADHD as a risk factor for incident unprovoked seizures and epilepsy in children. Arch Gen Psychiatry. 2004;61:731-736. doi:10.1001/archpsyc.61.7.731

23. Reilly C, Ballantine R. Epilepsy in school-aged children: more than just seizures? Support Learn. 2011;26:144-151. doi:10.1111/j.14679604.2011.01501.x

24. Okumura A, Saitoh S, Natsume J, et al. Attitudes of school teachers toward epilepsy in Nagoya, Japan. Epilepsy Behav. $2020 ; 103: 106359$. doi:10.1016/j.yebeh.2019.06.005

25. Al-Hashemi E, Ashkanani A, Al-Qattan H, et al. Knowledge about epilepsy and attitudes toward students with epilepsy among middle and high school teachers in Kuwait. Int J Pediatr. 2016;2016:1-15. doi:10.1155/2016/5138952

26. Alhambra H, Tannous A, Hadidi M, et al. Knowledge and attitudes toward epilepsy among school teachers and counselors in Jordan. Epilepsy Behav. 2012;24:430-434. doi:10.1016/j.yebeh.2012.05.004 
27. Al-Harbi AF, Alsaid LA, Parameaswari PJ. Primary school female teachers' knowledge, attitude, and practice toward students with epilepsy in Riyadh, Saudi Arabia. Fam Med Prim Care. 2018;7:331. doi:10.4103/jfmpc.jfmpc_58_18

28. Al-Ruwaili LH, Youssef AM, Al-Shehri WD, et al. Saudi teachers' knowledge and practices related to management of students with epilepsy. Med J Cairo. 2019;87:763-768.

29. Alamri S, Alghamdi A, Al Quiet A. What Saudi teachers know about epilepsy: a cross-sectional study of Tabuk City. Epilepsy Behav. 2018;89:169-172. doi:10.1016/j.yebeh.2018.10.024

30. Alkhotani AM, Almalki WM, Alkhotani AM, et al. Makkah female teachers' knowledge of seizure first aid. Epilepsy Behav. 2019;98:10-13. doi:10.1016/j.yebeh.2019.05.047

31. Alamri S, Al Thobaity A. Teachers and epilepsy: what they know, do not know, and need to know: a cross-sectional study of Taif City. Fam Med Prim Care. 2020;9:2704. doi:10.4103/jfmpc.jfmpc_33_20

32. Alzhrani SH, AlSufyani MH, Abdullah RI, et al. Schoolteacher's knowledge, attitudes, and practice toward student with epilepsy in Taif, Saudi Arabia: cross-sectional study. Fam Med Prim Care. 2021;10(7):2668. doi:10.4103/jfmpc.jfmpc_2087_20

33. Obeid T, Abulaban A, Al-Ghatani F, et al. Possession by 'Jinn'as a cause of epilepsy (Saraa): a study from Saudi Arabia. Seizure. 2012;21 (4):245-249. doi:10.1016/j.seizure.2012.01.001

34. Alqahtani JM. Knowledge and practice of schoolteachers towards students with epilepsy in Khamis Mushate, Southern Saudi Arabia. J Fam Community Med. 2015;22:163. doi:10.4103/2230-8229.163034

35. Kanjo M, Najjar A, Bokhari AY, et al. Knowledge of epilepsy and seizure first aid among teachers in Jeddah, Saudi Arabia. Epilepsy Behav Rep. 2021;16:100475. doi:10.1016/j.ebr.2021.100475

36. Jones C, Atkinson $\mathrm{P}$, Cross $\mathrm{JH}$, et al. Knowledge of and attitudes towards epilepsy among teachers: a systematic review. Epilepsy Behav. 2018;87:59-68. doi:10.1016/j.yebeh.2018.06.044

37. AlHarbi FA, Alomari MS, Ghaddaf AA, et al. Public awareness and attitudes toward epilepsy in Saudi Arabia: a systematic review and meta-analysis. Epilepsy Behav. 2021;124:108314. doi:10.1016/j.yebeh.2021.108314

38. Gebrewold MA, Enquselassie F, Teklehaimanot R, et al. Ethiopian teachers: their knowledge, attitude and practice towards epilepsy. BMC Neurol. 2016;16(1):1-8. doi:10.1186/s12883-016-0690-4

39. Assadeck H, Toudou Daouda M, Moussa Konate M, Mamadou Z, Douma Maiga D, Sanoussi S. Knowledge, attitudes, and practices with respect to epilepsy among primary and secondary school teachers in the city of Niamey, Niger. Brain Behav. 2020;10:e01539. doi:10.1002/brb3.1539

40. Toudou-Daouda M, Ibrahim-Mamadou AK. Teachers' knowledge about epilepsy and their attitudes toward students with epilepsy: a cross-sectional survey in the city of Tahoua (Niger). Neuropsychiatr Dis Treat. 2020;16:2327. doi:10.2147/ndt.S276691

41. Sansa E, Fray S, Jamoussi H, et al. Knowledge and attitudes toward epilepsy among teachers in Tunisia. Epilepsy Behav. 2021;123:108260. doi:10.1016/j.yebeh.2021.108260

42. Papathanasopoulos PG, Tsibri ES, Gourzoulidou E, et al. Near-deadly resuscitation during a grand mal seizure. Epilepsia. 2004;45(9):1164. doi:10.1111/j.0013-9580.2004.21604.x

43. O'Hara KA. First aid for seizures: the importance of education and appropriate response. J Child Neurol. 2007;22:30S-37S. doi:10.1177/ 0883073807303066

44. Trinka E, Cock H, Hesdorffer D, et al. A definition and classification of status epilepticus - report of the ILAE task force on classification of status epilepticus. Epilepsia. 2015;56(10):1515-1523. doi:10.1111/epi.13121

45. Wait S, Lagae L, Arzimanoglou A, et al. The administration of rescue medication to children with prolonged acute convulsive seizures in the community: what happens in practice? Eur J Paediatr. 2013;17(1):14-23. doi:10.1016/j.ejpn.2012.07.002

46. Eze CN, Ebuehi OM, Brigo F, et al. Effect of health education on trainee teachers' knowledge, attitudes, and first aid management of epilepsy: an interventional study. Seizure. 2015;33:46-53. doi:10.1016/j.seizure.2015.10.014

47. Abou Khaled KJ, Ibrahim MI, Moussa RF. Impact of epilepsy training on school teachers and counselors: an intervention study in Lebanon. Epilepsy Behav Rep. 2020;14:100365. doi:10.1016/j.ebr.2020.100365

48. Goel S, Singh N, Lal V, et al. Evaluating the impact of comprehensive epilepsy education programme for school teachers in Chandigarh city, India. Seizure. 2014;23(1):41-46. doi:10.1016/j.seizure.2013.09.010

49. Tavares TP, Kerr EN, Secco M, et al. Brief video enhances teacher trainees' knowledge of epilepsy. Epilepsy Behav. 2021;118:107963. doi:10.1016/ j.yebeh.2021.107963

50. Mecarelli O, Messina P, Capovilla G, et al. An educational campaign about epilepsy among Italian primary school teachers. 2. The results of a focused training program. Epilepsy Behav. 2015;42:93-97. doi:10.1016/j.yebeh.2014.07.022

51. Hart Barnett JE, Gay C. Accommodating students with epilepsy or seizure disorders: effective strategies for teachers. Phys Disabilities. 2015;34 (1): $1-3$.

\section{Publish your work in this journal}

The International Journal of General Medicine is an international, peer-reviewed open-access journal that focuses on general and internal medicine, pathogenesis, epidemiology, diagnosis, monitoring and treatment protocols. The journal is characterized by the rapid reporting of reviews, original research and clinical studies across all disease areas. The manuscript management system is completely online and includes a very quick and fair peer-review system, which is all easy to use. Visit http://www.dovepress.com/testimonials.php to read real quotes from published authors.

Submit your manuscript here: https://www.dovepress.com/international-journal-of-general-medicine-journal 